\title{
Normal and Tangential Force Modeling and Control of Single Crystal Silicon Using Wire Saw Velocity Reciprocation
}

\section{Jiabin Wang}

Xi'an University of Technology

Shujuan Li ( $\sim$ shujuanli@xaut.edu.cn )

Xi'an University of Technology https://orcid.org/0000-0003-2060-1834

Lie Liang

Xi'an University of Technology

Zheng Hao

Xi'an University of Technology

\section{Feilong Liu}

Xi'an University of Technology

\section{Research Article}

Keywords: Cutting Force Modeling, Cutting Force Control, Single Crystal Silicon, Wire Saw Velocity, Surface roughness.

Posted Date: January 28th, 2022

DOI: https://doi.org/10.21203/rs.3.rs-1234927/v1

License: (c) (1) This work is licensed under a Creative Commons Attribution 4.0 International License. Read Full License 


\title{
Normal and Tangential Force Modeling and Control of single crystal Silicon using Wire Saw Velocity Reciprocation
}

\author{
Jiabin Wang Shujuan Li Lie Liang Zheng Hao Feilong Liu \\ 806406143@qq.com, shujuanli@xaut.edu.cn, 471998770@qq.com, \\ 1006343425@qq.com, 105071@xaut.edu.cn
}

School of Mechanical and Instrument Engineering, Xi'an University of

Technology, 5 South Jinhua Road, Xi'an, Shaanxi 710048,

Abstract: Single crystal silicon wafer is widely used as the substrate material for integrated circuits, and the wafer is cut by wire saw with fixed diamond abrasive owning to the wire saw's narrow kerf, low cutting force. The cutting force changes during the process operation since the wire change motion direction continuously (i.e., reciprocation) in order to effectively leverage the wire, even if the contact length of wire and part and wire saw tension are fixed, leading to wire saw breakage, wafer collapse, and inferior surface roughness. This paper established the model of cutting force that includes normal force and tangential force, and design the controller for regulating the force via wire velocity control, and the controller obtains the relationship between the normal force and commanded wire velocity. A PI controller experimental studies for Single crystal Silicon wafer wire saw machining are conducted. The results show the controller can well regular the cutting force generated when wire saw machines silicon and on that the wire saw machining process with PI control can decrease wafer surface roughness as compared to the 
cutting process with a constant wire velocity reciprocation.

Keywords: Cutting Force Modeling; Cutting Force Control; Single Crystal Silicon; Wire Saw Velocity; Surface roughness.

\section{Introduction}

Hard and brittle materials such as single crystal silicon and sapphire are being used more and more in integrated circuitry and photoelectricity. However, the processing requirements, such as thinner wafer thicknesses, reduced warping and reduced total thickness variation, are becoming more stringent. Fixed diamond abrasive wire saw machining is used for cutting hard and brittle materials due to its flexibility, narrow kerf and low cutting force. The cutting force changes during the process operation due to changes in the contact length of part and wire and wire direction, variations in the process parameters, wire wear, etc. This change in cutting force can lead to wire saw breakage, wafer collapse and increased wafer surface roughness. Therefore, controlling the cutting force is vital to improving operation productive and wafer quality.

Wire saw machining has been developed for slicing hard and brittle materials into thin wafers since the 1990s. Clark et al. ${ }^{[1]}$ observed that the free abrasives in slurry between the wire and part, making hard and brittle materials difficult to machine due to the decreased cutting velocity and uneven wafer thickness resulting from wire wear. Ishikawa et al. ${ }^{[2]}$ observed 
that when a wafer diameter is close to 6 inch, wire sawing with loose abrasives increases the cutting time as it is difficult to supply abrasives to the wafer center. Watanabe et al. ${ }^{[3]}$ discussed the properties of the wafers sliced using a fixed abrasive wire saw.

Yin Y. et al. ${ }^{[4]}$, established a mathematical model of diamond wire sawing based on the machining mechanism of brittle material removal and surface generation, and the numerical calculation of the sawing process was carried out. Chung C. et al. ${ }^{[5]}$ established a model to simulate the distribution of diamond grains. The simulation demonstrate that a higher density distribution reduces the rate of material removal because the loading is shared by the abrasives, thereby preventing the grains from penetrating deeply enough into the workpiece to facilitate the removal of material. Lower distribution density was shown to increase the loadings on the abrasives. Clark et al. $[1,6]$ investigated the process monitoring and mechanics of fixed abrasive diamond wire saw machining, show it is the promising machining method for brittle and materials. Li and Tsai ${ }^{[7]}$ presented a machine vision-based scheme to automatically detect saw-mark defects in Si wafer surfaces. Cao ${ }^{[8]}$ described the hydraulic control system of a diamond wire saw. The closed-loop velocity control system was established based on typical process parameters for the diamond wire saw process. Zhu and Kao ${ }^{[9]}$ found the surface roughness of a wafer with wire saw-sliced is usually not uniform, leading to the subsequent lapping and polishing processes less productive. 
Liedke and Kuna ${ }^{[10]}$ developed an analytical model for the macroscopic mechanical conditions in the wire saw process, which describes the influence of several process parameters to the cutting pressure.

Li et al. ${ }^{[11]}$ have established a control model to control the normal force by using feed as a control variable. The experiment results showed that the wire saw machining process with adaptive force control can improve the cutting productivity and significantly decrease wafer surface roughness as compared to the cutting process with a constant part feed rate. Li et al. ${ }^{[12]}$ use optic glass as test material, conducted an experiment of normal force control by wire velocity, and experiments showed that the wire velocity controllers are possible.

Based on the previous research ${ }^{[12,13]}$, this paper investigates the cutting force control of single crystal silicon using wire saw velocity as the control signal. To understand the influence of wire velocity on the cutting force (include normal force and tangential force), this paper develops a model of normal cutting force and tangential force relating wire velocity. Based on the model, an on-line Proportion and Integral (PI) controller is designed to maintain a constant force, and is experimentally implemented. The cutting productivity, wafer topography and surface roughness are investigated when wire saw machining single crystal silicon with and without force control.

\section{Cutting Principle and Equipment}

Figure 1 shows a schematic of the wire saw cutting single crystal silicon, a 
wire saw wound roller, two work idler pulleys and an moving wheel form the wire feed mechanism. Both ends of the wire saw are fixed at the wire drum roller, and two travel switches in the bottom of the wire drum roller achieve the shifting action for the wire direction. The wire saw tension adjusts by moving wheel with up and down motion, and the single crystal silicon is mounted in the workbench, which feeds towards the wire.

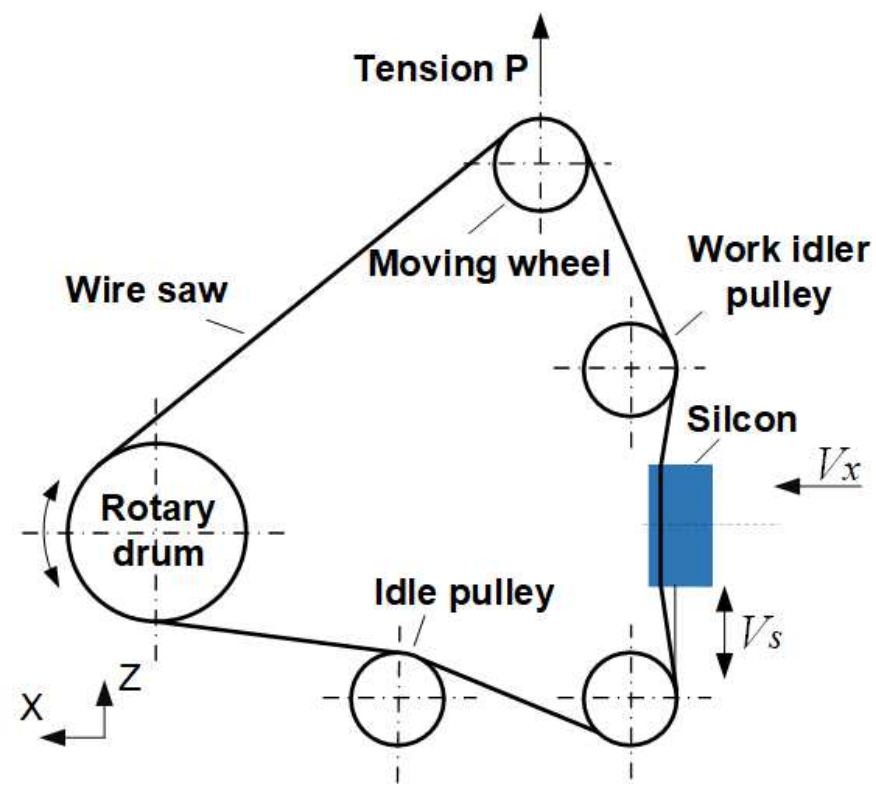

Fig. 1: Wire saw machining schematic.

The part move in the $X$ and $Y$ directions via stepper motors. The $X$-direction is the part feed direction and the $Y$ direction is used to regulate the wafer thickness and remains constant during the operation. The $X$ and $Y$ axis ranges are $0-120 \mathrm{~mm}$, the part feed rate range is $0.025-18 \mathrm{~mm} / \mathrm{min}$. The wire saw base is made from a high-quality stainless steel and is nickel plated with a JR2 type diamond abrasive having an average abrasive grain size of $30-40$ $\mu \mathrm{m}$. The wire has a length $86 \mathrm{~m}$, an average diameter of $0.24 \mathrm{~mm}$ and the velocity range is $0-3 \mathrm{~m} / \mathrm{s}$, and the feed rate is $0-3 \mathrm{~mm} / \mathrm{min}$. The moving wheel 
can regulate the wire tension in the range of 0-0.6 MPa. A Gamma SI-32-2.5-type six-component dynamometer from the ATI Company is used to measure the normal force. It has a range of $100 \mathrm{~N}$ and a resolution of $1.25 \times 10^{-2} \mathrm{~N}$

\section{Modeling Wafer Cutting Force}

Wafer cutting force includes normal force, tangential force and longitude force, the normal force and tangential force, which show in Fig. 2. The force is variable during the whole cutting period, it's difficult to show the force vary by quantitative model. And during the wafer cutting process, the longitude force (in $\mathrm{Y}$ direction) is nearly zero. The normal force and tangential force influence the wafer surface roughness. This study considers the normal force and tangential force varies with wire velocity.

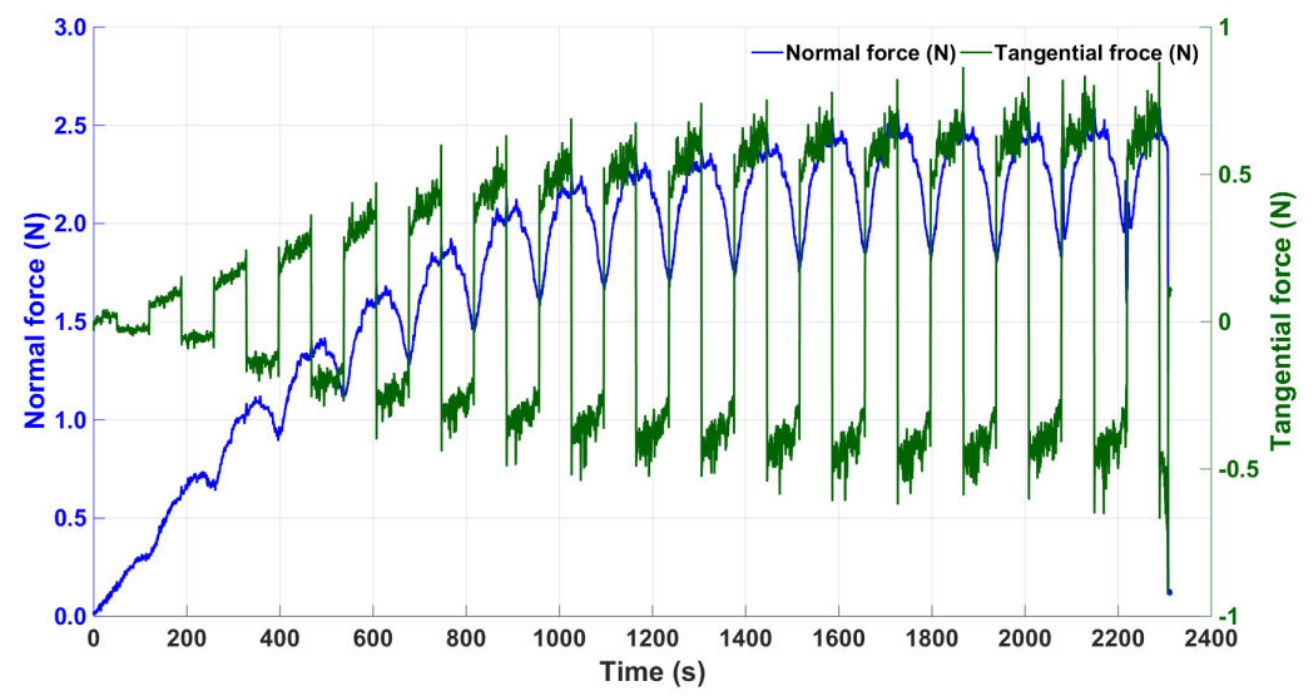

Fig. 2: The normal force and tangential force in wire saw machining. ( $\mathrm{Vs}=1.5 \mathrm{~m} / \mathrm{s}$, $\mathrm{V} x=0.75 \mathrm{~mm} / \mathrm{min}$ )

\subsection{The cutting force analysis}

(1) Firstly, let's analyzing the relation of the pressure and indentation depth of 
single abrasive. Fig. 3 shows the SEM picture of wire saw electroplated with diamond abrasives. To simplify the analytic process, the model of single abrasive is considered as wedge, as shows in Fig. 4.

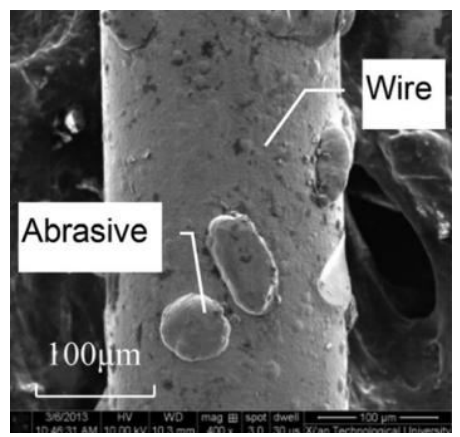

Fig. 3: The SEM picture of wire saw electroplated with diamonds.

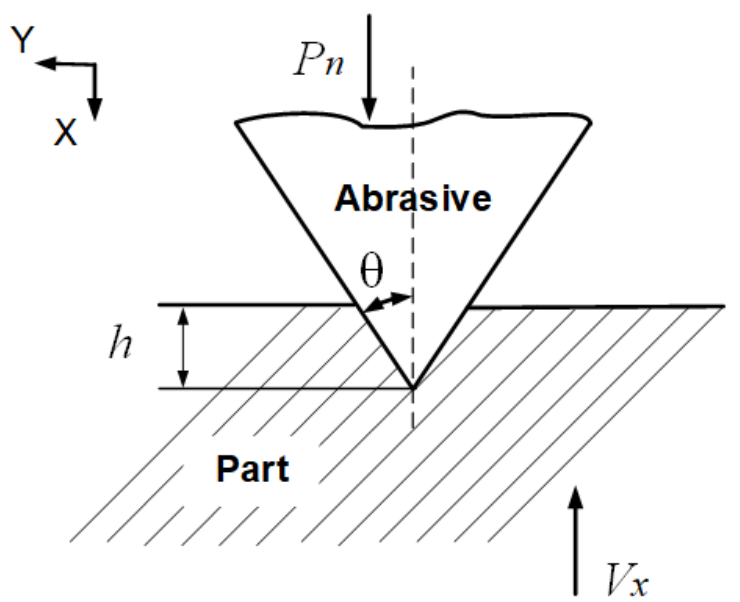

(a)

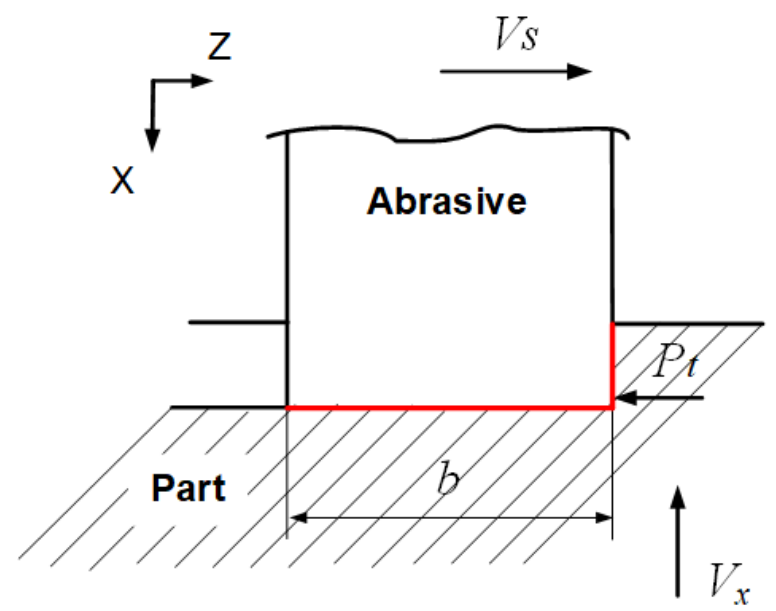

(b)

Fig. 4: The force illustration of single abrasive model. 
Considering the depth calculation of a single abrasive pressed into the part, based on the sliding line field theory ${ }^{[13]}$, the plastic deformation model formed by the wedge tool pressing, as shows in Fig. 5 .

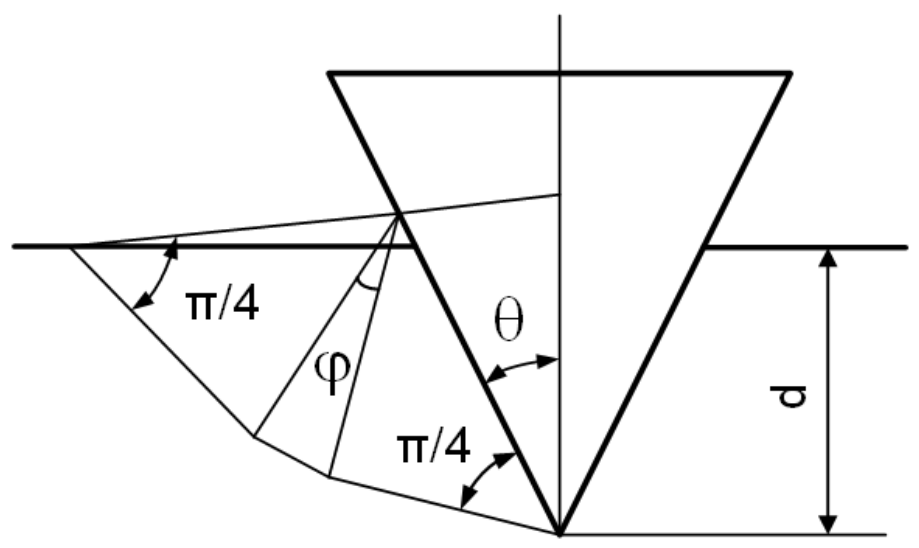

Fig. 5: Slip line model of wedge type tool indentation.

According to Fig. 5 , it can get

$$
\cos (2 \theta-\varphi)=\frac{\cos \varphi}{1+\sin \varphi}
$$

where $\theta$ is the knife edge tool is 30 degrees, and $\varphi=17.4$ degrees is calculated by eq.(1). Based on this model, it can get

$$
p / d=\left\{2(1+\varphi) \frac{\sin \theta}{\cos \theta-\sin (\theta-\varphi)} b\right\} \sigma_{0}
$$

where $p / d$ is load/depth ratio. $b$ is the width of the abrasive, $d$ is the indentation depth, and $\sigma_{0}$ is yield stress of material.

Based on the equation (2), $h$ is indentation depth of abrasive, it can get

$$
P_{n}=\left\{2(1+\varphi) \frac{\sin \theta}{\cos \theta-\sin (\theta-\varphi)} b\right\} \sigma_{0} h
$$

Where $P_{n}$ is the penetration force, $h$ is the indentation depth of abrasive.

(2) During the cutting process, the main force is chip forming force and 
friction force, which are the distribution force of the vertical abrasive to the center of the abrasive at the contact surface with the part and the distribution force along the opposite direction of the contact surface and the speed of the wire saw ${ }^{[14]}$. Fig. 6 shows the schematic diagram for wire saw cutting process, and $l_{a}(\mu \mathrm{m})$ is the distance between two abrasives, $V_{s}(\mathrm{~m} / \mathrm{s})$ is wire velocity and $V_{x}(\mathrm{~mm} / \mathrm{min})$ is part feed rate.

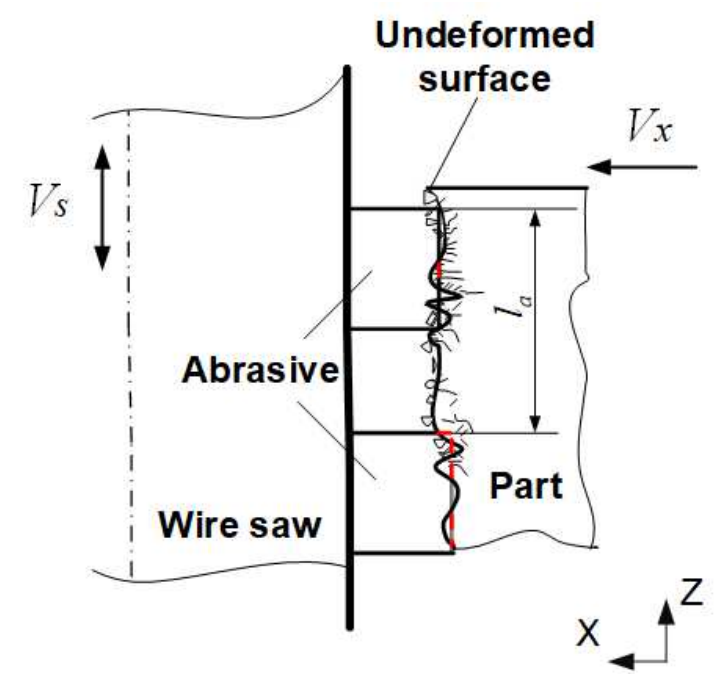

Fig. 6: A schematic diagram for wire saw cutting process.

The normal cutting force $F_{n}(\mathrm{~N})$, tangential cutting force $F_{t}(\mathrm{~N})$ are sum of all abrasives involved cutting process, respectively.

$$
F_{n}=\sum_{i=1}^{N_{a}} p_{n i}, F_{t}=\sum_{i=1}^{N_{a}} p_{t i}
$$

where

$$
N_{a}=\frac{V_{s}}{V_{x} l_{a}}
$$

The abrasive number $N_{a}$ of involved cutting depend on the feed rate and wire saw velocity.

Cutting force $F_{n}, F_{t}$ are sum of varies abrasives penetration force involved 
into cutting. According equation (5), the force vary with the abrasives size, however, the size of the abrasive varies randomly within a certain range, and the shapes vary in practice. Besides, the properties of single crystal silicon at different positions contacting with the abrasives on the wire saw is different. As a result, the cutting forces on the abrasives in different positions is different ${ }^{[15]}$. It is difficult to quantify accurately the cutting force and then to control using the theoretical model. Therefore, the experimental method is used to establish a cutting force model with wire velocity and part feed rate.

\subsection{The normal cutting force modeling}

In order to find relation between rectangle silicon cutting force and wire saw velocity, experiments are designed to build a model. The part is single crystal silicon, and the size is $220 \times 20 \times 26 \mathrm{~mm}$, the wire saw length is $106 \mathrm{~m}$, and the radius, is $0.12 \mathrm{~mm}$, the contact length between wire saw and part is 26 $\mathrm{mm}$, the part feed rate is $0.75 \mathrm{~mm} / \mathrm{min}$. Table 1 lists the process parameters and cutting forces and processing times are in the experiments.

Table 1: The process parameters and cutting forces and processing times.

\begin{tabular}{cccccc}
\hline & $V_{s}(\mathrm{~m} / \mathrm{s})$ & $V_{x}(\mathrm{~mm} / \mathrm{min})$ & $F_{n}(\mathrm{~N})$ & $F_{t}(\mathrm{~N})$ & Processing Time $(\mathrm{s})$ \\
\hline 1 & 1.0 & 0.75 & 2.720 & 0.692 & 2538 \\
2 & 1.5 & 0.75 & 2.195 & 0.484 & 2314 \\
3 & 2.0 & 0.75 & 1.746 & 0.395 & 2161 \\
\hline
\end{tabular}

The cutting force profiles show in Fig. 7 , when wire saw velocity is $1.0,1.5$ and $2.0 \mathrm{~m} / \mathrm{s}$ and the part feed rate is $0.75 \mathrm{~mm} / \mathrm{min}$. From the Fig. 7, the normal cutting force decreases with the wire saw velocity increase. Fig. 8 is the relation between normal force and wire velocity of $1.5 \mathrm{~m} / \mathrm{s}$, and the 
upper-left corner of the graph is the zoom in of relation between normal force and wire velocity of $1.5 \mathrm{~m} / \mathrm{s}$.

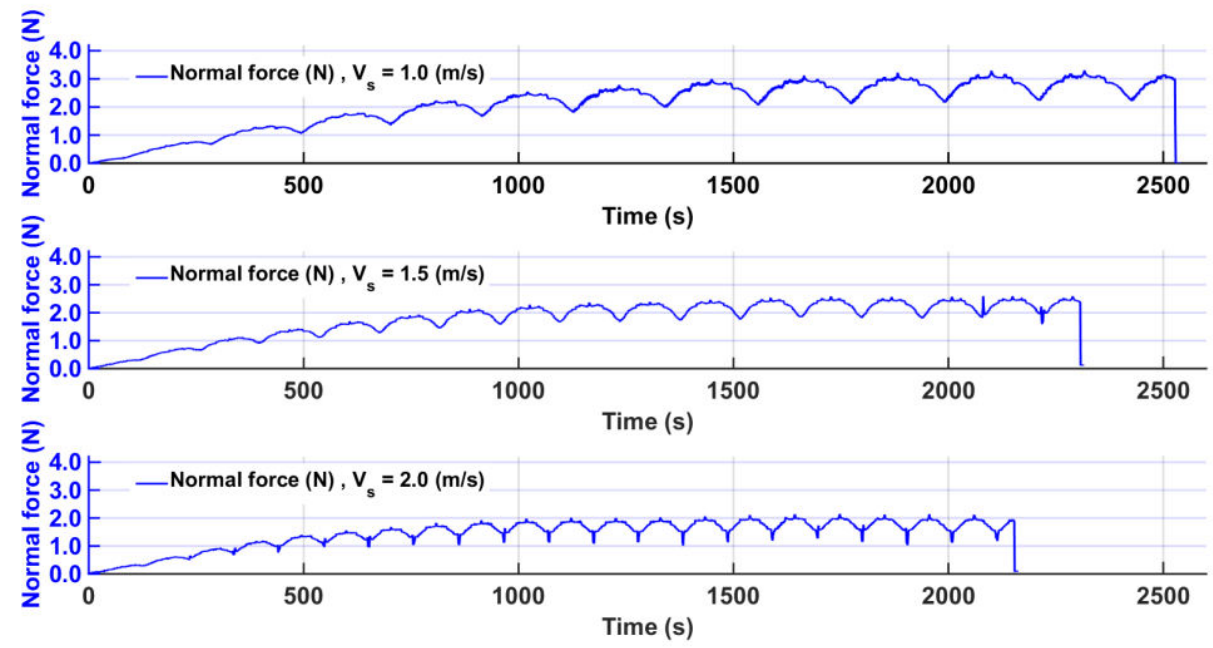

Fig. 7: Normal cutting force profiles for wire saw velocities of $1.0,1.5$ and $2.0 \mathrm{~m} / \mathrm{s}$ when feed rate is $0.75 \mathrm{~mm} / \mathrm{min}$.
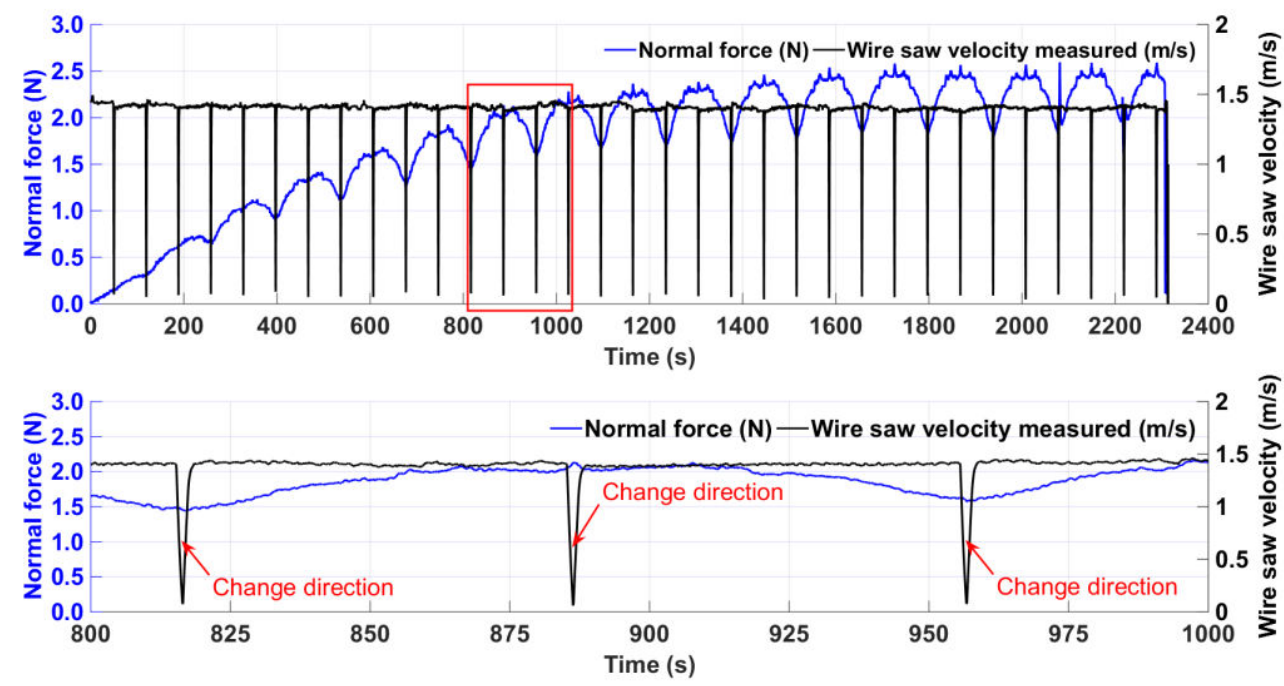

Fig. 8: Normal cutting force profiles for wire saw velocities of $1.5 \mathrm{~m} / \mathrm{s}$ when feed rate is $0.75 \mathrm{~mm} / \mathrm{min}$. (Zoom in of normal cutting force profiles)

The model obtain from the experiments ${ }^{[16]}$ is

$$
F_{n}(t)=K_{n} V_{x}(t)^{\alpha} V_{s}(t)^{\beta}
$$

where $F_{n}(t)$ is the normal cutting force, $\alpha$ and $\beta$ is the exponential of part feed rate and wire velocity. Least square is used to get the $F_{n}(t), \alpha$ and $\beta$ which is $2.9641,0.6941$ and -0.7059 , respectively. The relation between cutting force 
and feed rate is increasing feed rate can improve the normal force, however, overlarge feed rate leads the wire bend and more large cutting force which lead to the wafer break and surface roughness inferior; therefore, based on the experience, the feed rate choose $0.75 \mathrm{~mm} / \mathrm{min}$. The normal force model is

$$
F_{n}(t)=2.74 V_{s}(t)^{-0.6154}
$$

\subsection{The tangential cutting force modeling}

Similarly, experiments are designed to build a model, to find relation between single crystal silicon cutting force and wire saw velocity. As table 1 lists the process parameters are used for the experiments. The tangential cutting force profiles show in Fig. 9 when the wire velocity is $1,1.5$ and $2.0 \mathrm{~m} / \mathrm{s}$ and the part feed rate is $0.75 \mathrm{~mm} / \mathrm{min}$. From the Fig. 9 , the tangential cutting force decreases with the wire saw velocity increases. Fig. 10 is the relation between tangential force and wire velocity of $1.5 \mathrm{~m} / \mathrm{s}$, and the bottom of the graph is the zoom in of relation between tangential force and wire velocity of $1.5 \mathrm{~m} / \mathrm{s}$ during $1000 \mathrm{~s}$ to $1200 \mathrm{~s}$.

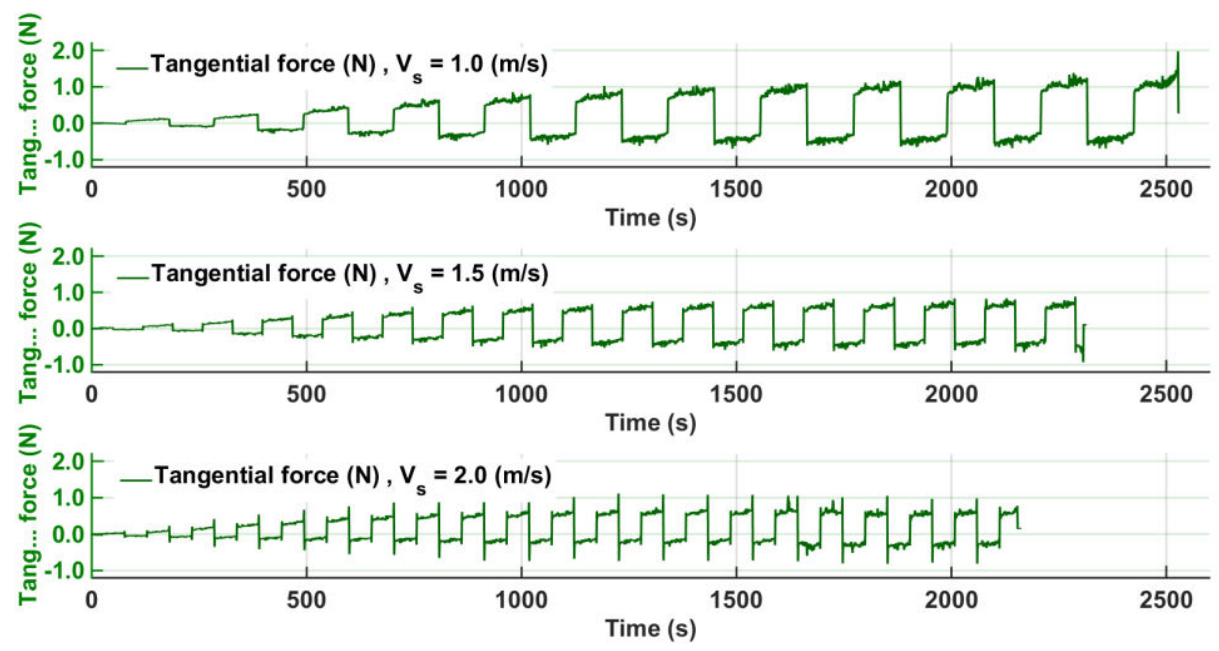

Fig. 9: Tangential cutting force profiles for wire saw velocities of $1,1.5$ and $2.0 \mathrm{~m} / \mathrm{s}$ when 
feed rate is $0.75 \mathrm{~mm} / \mathrm{min}$.
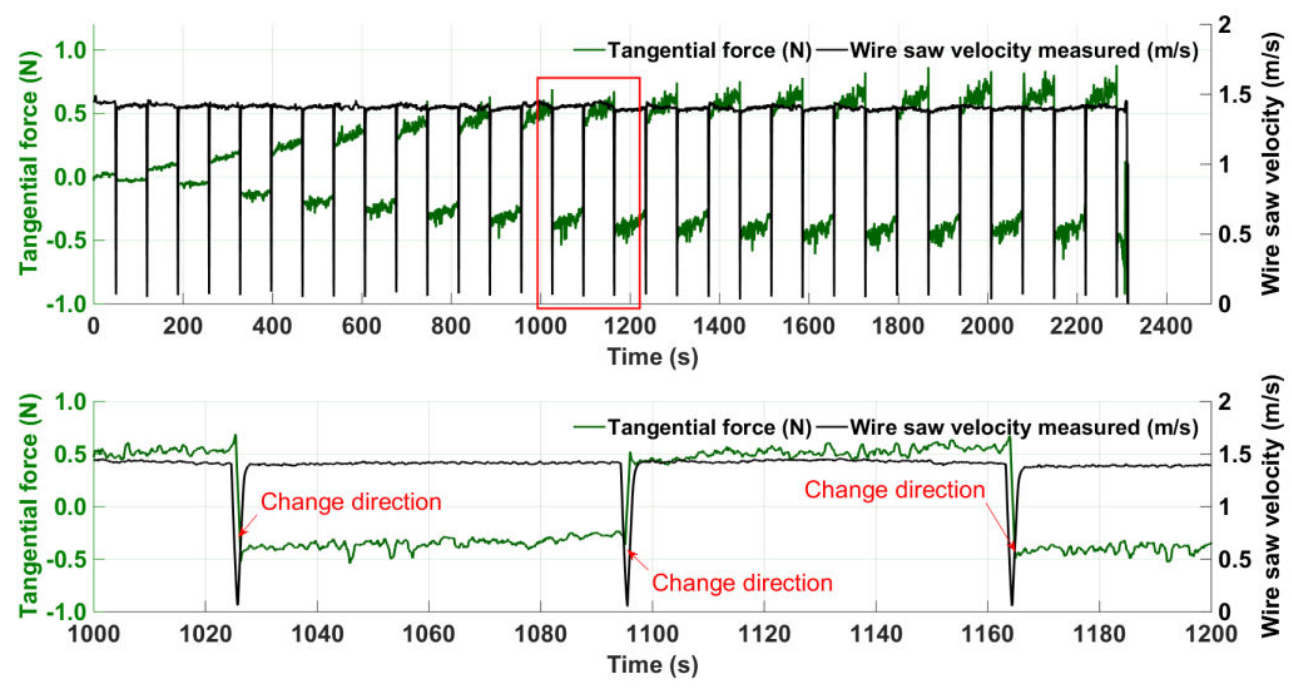

Fig. 10: Tangential cutting force profiles for wire saw velocity of $1.5 \mathrm{~m} / \mathrm{s}$ when feed rate is $0.75 \mathrm{~mm} / \mathrm{min}$, zoom in $1000 \mathrm{~s}$ to $1200 \mathrm{~s}$.

The tangential force model obtain from the experiments is

$$
F_{t}(t)=0.6894 V_{s}(t)^{-0.8276}
$$

\section{Controller design with Wire Velocity Control}

Linearizing Eq. (6)

$$
\Delta F_{n, t}(t)=\left[K_{s} \beta\left(\bar{V}_{s}\right)^{\beta-1}\right] \Delta V_{s}(t)
$$

where the incremental normal force is $\Delta F_{n}(t)=F_{n}(t)-\bar{F}_{n}$, the nominal normal force is $\bar{F}_{n}=\bar{F}_{r}$, where $\bar{F}_{r}$ is the nominal reference force $(\mathrm{N})$, the incremental wire velocity is $\Delta V_{s}(t)=V_{s}(t)-\bar{V}_{s}$ and the nominal wire velocity is

$$
\bar{V}_{s}=\left[\frac{\bar{F}_{r}}{K_{s}}\right]^{(1 / \beta)}
$$

The wire saw dynamics are

$$
\tau \dot{V}_{s}(t)=-V_{s}(t)+K_{w} V_{c}(t)
$$

where $\tau=0.787 \mathrm{~s}$ is the time constant, which is determined experimentally, $K_{w}$ 
$=1$ is the gain and the $V_{c}$ is the commanded wire saw velocity. Linearizing Eq. (20)

$$
\tau \Delta \dot{V}_{s}(t)=-\Delta V_{s}(t)+K_{w} \Delta V_{c}(t)
$$

where $\Delta V_{c}(t)=V_{c}(t)-\bar{V}_{c}$ is the incremental command wire velocity. The nominal command wire saw velocity is $\bar{V}_{c}=\bar{V}_{s}$. The transfer function relating the incremental normal force to the incremental command wire saw velocity is

$$
\frac{\Delta F_{n, t}(s)}{\Delta V_{c}(s)}=\left[\beta\left(\overline{V_{s}}\right)^{\beta-1}\right] \frac{K_{s}}{\tau s+1}
$$

The transfer function for a Proportional plus Integral (PI) controller is

$$
\frac{\Delta V_{c}(s)}{\Delta E_{n, t}(s)}=\frac{K_{p} s+K_{i}}{s}
$$

where $K_{p}$ is the proportional gain $(\mathrm{m} / \mathrm{s} / \mathrm{N}), K_{i}$ is the integral gain $\left(\mathrm{m} / \mathrm{s}^{2} / \mathrm{N}\right)$ and the incremental normal force error is

$$
\Delta E_{n, t}(s)=\Delta F_{r}(s)-\Delta F_{n, t}(s)
$$

Combining Eq. (9)-(11), the closed-loop transfer function is

$$
\frac{\Delta F_{n, t}(s)}{\Delta F_{r}(s)}=\frac{\tau^{-1}\left(K_{p} s+K_{i}\right) K_{s} \beta\left(\overline{V_{s}}\right)^{\beta-1}}{s^{2}+\tau^{-1}\left[1+K_{p} K_{s} \beta\left(\overline{V_{s}}\right)^{\beta-1}\right] s+\tau^{-1} K_{i} K_{s} \beta\left(\overline{V_{s}}\right)^{\beta-1}}
$$

Designing the closed-loop system to be overdamped with two time constants, $\tau_{1}$ and $\tau_{2}$, the controller gains are

$$
K_{p}=\frac{\left(\tau_{1}^{-1}+\tau_{2}^{-1}\right) \tau-1}{K_{s} \beta\left(\overline{V_{s}}\right)^{\beta-1}} \quad K_{i}=\frac{\tau_{1}^{-1} \tau_{2}^{-1} \tau}{K_{s} \beta\left(\bar{V}_{s}\right)^{\beta-1}}
$$

The controller difference equation is

$$
V_{c}(i)=V_{c}(i-1)+K_{p}\left[\Delta E_{n}(i)-\Delta E_{n}(i-1)\right]+K_{i} \Delta E_{n}(i) d t
$$

where $d t$ is the sample period (s). To ensure integral windup does not occur, 
the incremental wire saw velocity is saturated via

$$
\begin{array}{lll}
\Delta V_{s}(t)=V_{\max }-\bar{V}_{s} & \text { if } & \Delta V_{s}(t) \geq V_{\max }-\bar{V}_{s} \\
\Delta V_{s}(t)=V_{\min }-\bar{V}_{s} & \text { if } & \Delta V_{s}(t) \leq V_{\min }-\bar{V}_{s}
\end{array}
$$

where $V_{\min }=0.5 \mathrm{~m} / \mathrm{s}$ is the minimum wire saw velocity and $V_{\max }=4 \mathrm{~m} / \mathrm{s}$ is the maximum wire saw velocity. The implemented wire saw velocity is $V_{s}(t)=\Delta V_{s}(t)+\bar{V}_{s}$. The control system block diagram is given in Fig. 11 .

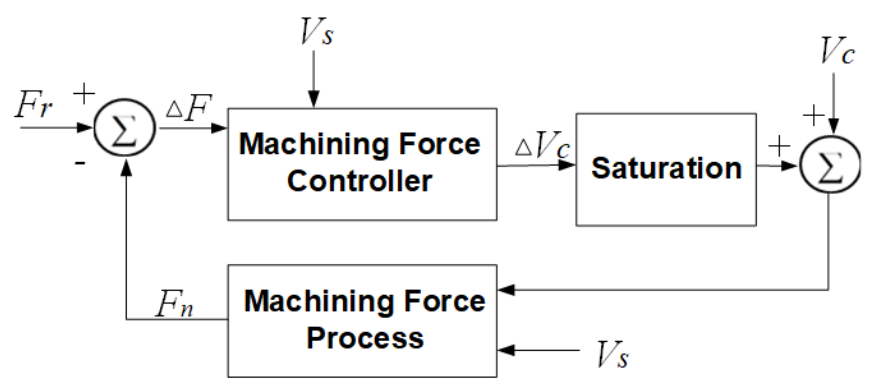

Fig. 11: Cutting force control system block diagram.

\section{Experimental Studies}

A schematic of the experimental wire saw machining system is shown in Fig. 12. The wire drum roller motor velocity is regulated by changing the voltage of DC motor driver, which is achieved by NI PXIe-6348 multi-function card. 


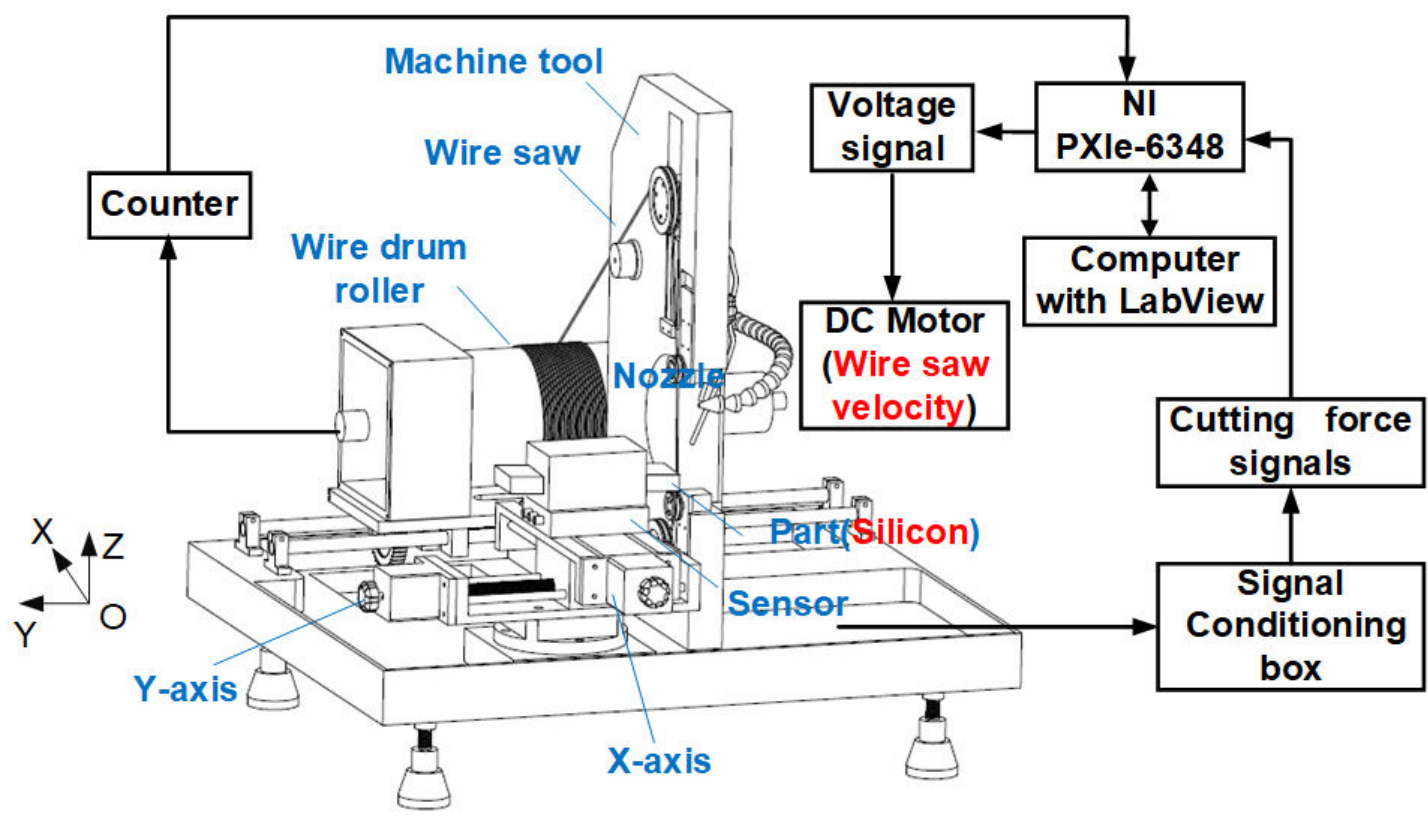

Fig. 12: Wire saw experimental system schematic.

The National Instruments PXle-6348 multifunction data acquisition system is used to collect process data, send the command, additional, the sample frequency is $10 \mathrm{~Hz}$. Comparing the difference between the measured and reference cutting forces, the computer sends a voltage signal to the potentiometer and adjusts the wire roller velocity accordingly. The program runs by LabView. In each experiment, the part size and process parameters are the same as constant velocities experiments before.

\subsection{The normal force control experiment}

In order to investigate the controller performance during the entire single crystal silicon wafer cutting process for different normal force, experiments utilizing reference normal forces of $2.3,2.0$ and $1.7 \mathrm{~N}$ are conducted, which corresponds to the normal force that wire velocity is $1,1.5$ and $2 \mathrm{~m} / \mathrm{s}$ and the part feed rate is $0.75 \mathrm{~mm} / \mathrm{min}$. The controller gains $K_{p}$ and $K_{i}$ are -5 and -0.001 , 
respectively. Fig. 13 shows the control results when reference normal forces is 2.3, 2.0 and $1.7 \mathrm{~N}$, respectively. From the Fig. 13, the controller start to regulate the wire velocity at 800,650 and 470 s when reference normal forces is $2.3,2.0$ and $1.7 \mathrm{~N}$, respectively. The force fluctuation is because the wire saw change direction constantly. When each wire saw change direction, the force is up and down which makes the difference between measured force and reference force change constantly which shows the controller work well.
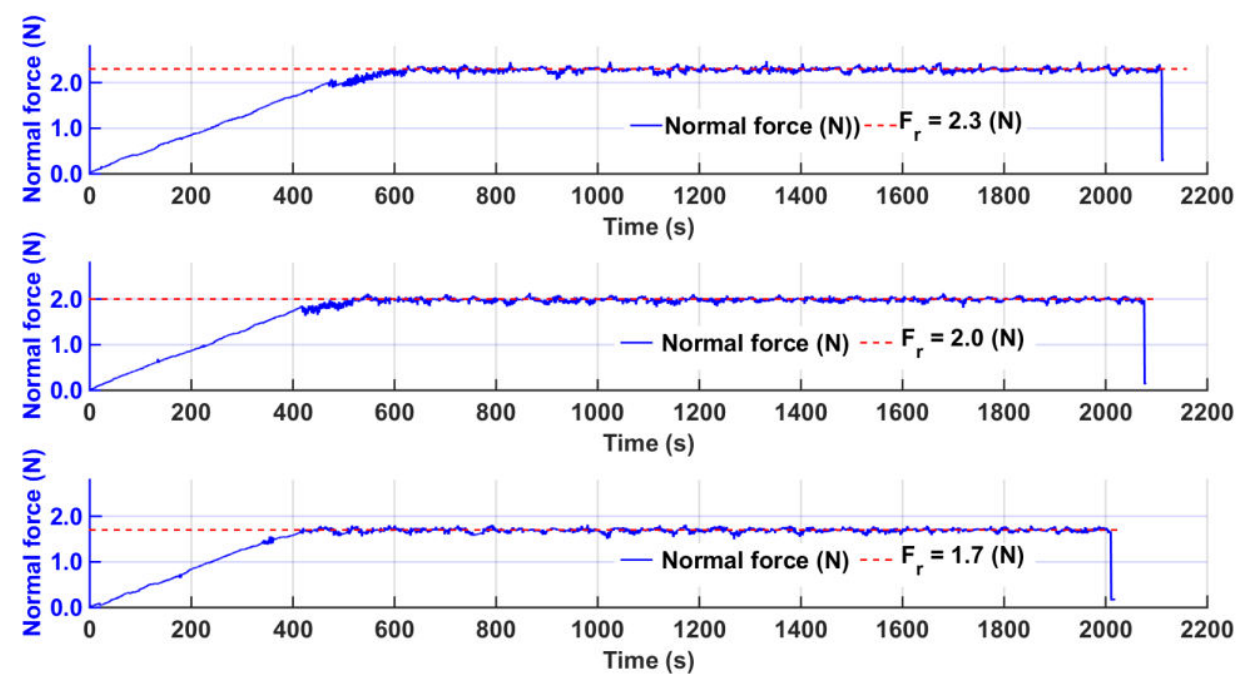

Fig. 13: the control results when reference normal forces is $2.4,2.0$ and $1.7 \mathrm{~N}$.

For the reference force $2.0 \mathrm{~N}$ which respond to the constant wire saw velocity approximate $1.5 \mathrm{~m} / \mathrm{s}$. The relation between normal force and command wire velocity shows in Fig. 14, with the zoom in relation between normal force and command wire velocity shows in Fig. 14 

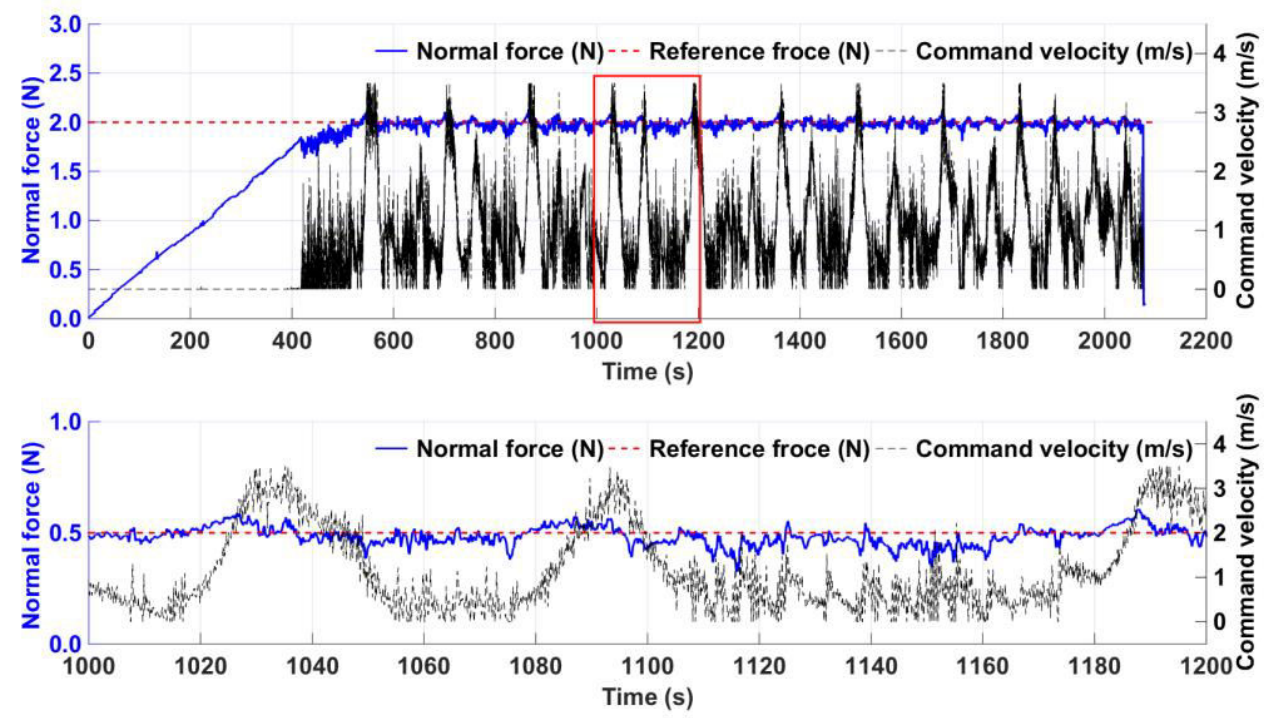

Fig. 14: The relation between normal force and command wire velocity with reference force $2.0 \mathrm{~N}$.

Figure 15 shows the comparison of normal force profile with control wire velocity with the reference force of $2.0 \mathrm{~N}$ and the wire velocity is $1.5 \mathrm{~m} / \mathrm{s}$. The cutting time is almost the same that is because the feed rate is the same $(0.75 \mathrm{~mm} / \mathrm{min})$ with and without control. The force fluctuation is much smaller with wire velocity which shows the controller works.

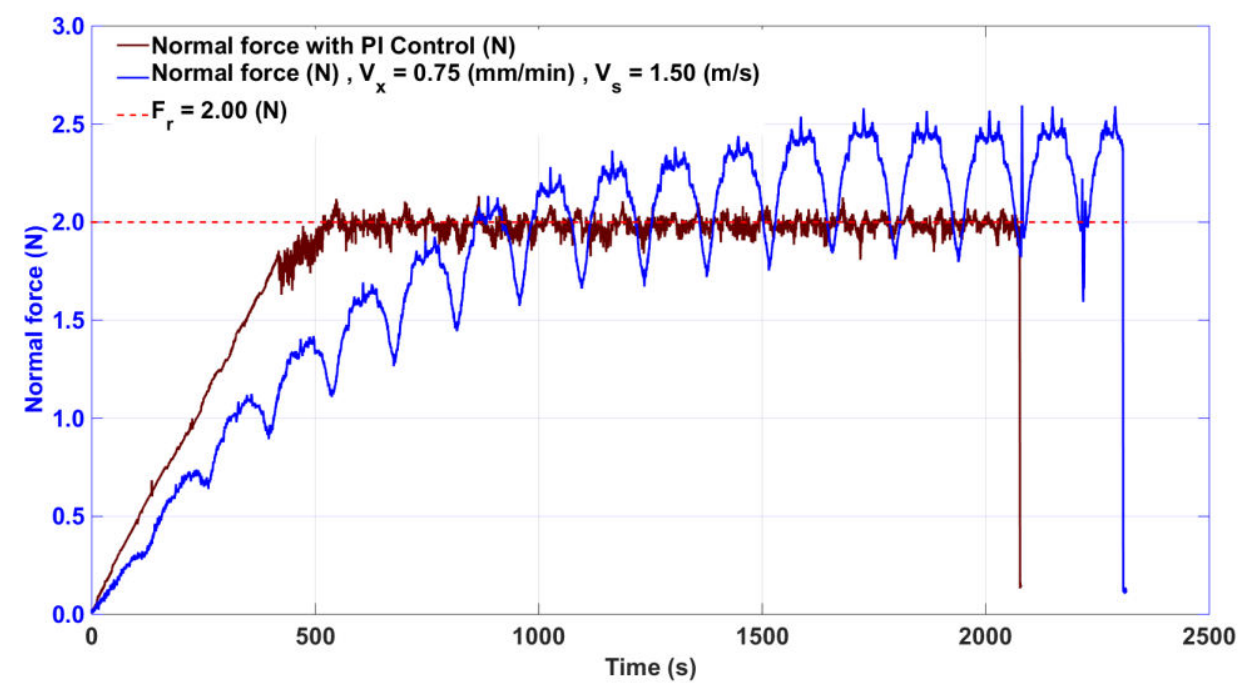

Fig. 15: Normal force Comparison.

The reason is the part feed is constant in the wire saw cutting process, and 
no matter the wire saw change direction or not. The constant feed lead to the wire bend when the wire saw stop cutting (change direction), hence, the normal force increase. When wire saw start cutting, the controller work on the wire velocity, since the wire is reciprocated, this control process varies with the wire reciprocate.

Additional, the results of the experiments are compared surface roughness of single crystal silicon wafer. Leica DCM3D is used to observe the topography of wafer, each wafer measures 6 points choose in the stable cutting status which the cutting force does not change. The measure range is $1.27 \mathrm{~mm} \times 0.42 \mathrm{~mm}$. The surface roughness of wafer is

$$
S a=\frac{1}{N M} \sum_{i=1}^{N} \sum_{j=1}^{M}\left|Z_{i j}\right|
$$

where, $N$ and $M$ are sample points along $\mathrm{X}$ and $\mathrm{Y}$ axis in measure zone, $Z$ is the height of $X$ and $Y$ axis in measure zone. The surface roughness is $12.42,9.98$ and $6.11 \mu \mathrm{m}$ for constant processing parameters of part feed rate is $0.75 \mathrm{~mm} / \mathrm{min}$ and wire velocity is $1,1.5$ and $2 \mathrm{~m} / \mathrm{s}$, respectively. The surface roughness is $6.25,3.53$ and $2.85 \mu \mathrm{m}$ when using the $\mathrm{PI}$ controller with part feed rate of $0.75 \mathrm{~mm} / \mathrm{min}$ and reference cutting force is $2.4,1.9$ and $1.48 \mathrm{~N}$, respectively. Figures 16, 17 and 18 show the comparison of surface roughness of single crystal silicon with feed rate $0.75 \mathrm{~mm} / \mathrm{min}$ and wire velocity $1,1.5$ and $2 \mathrm{~m} / \mathrm{s}$ and varies wire velocity. The comparing the cutting time and surface roughness with and without wire velocity control is in Table 2. 


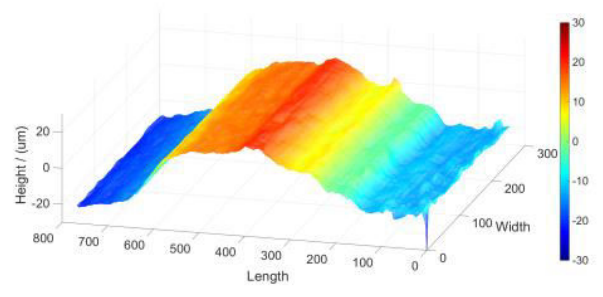

(a)

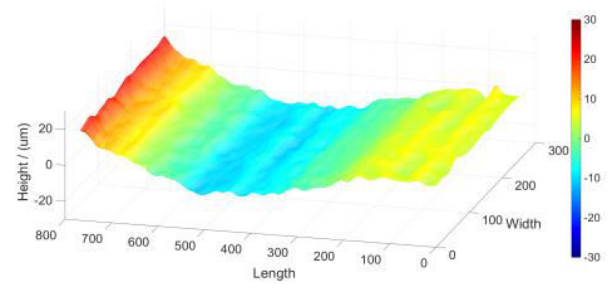

(b)

Fig. 16: Surface roughness of single crystal silicon with $V x=0.75 \mathrm{~mm} / \mathrm{min}$ and (a) $\mathrm{Vs}=1$ $\mathrm{m} / \mathrm{s}$, (b) varies wire velocity.

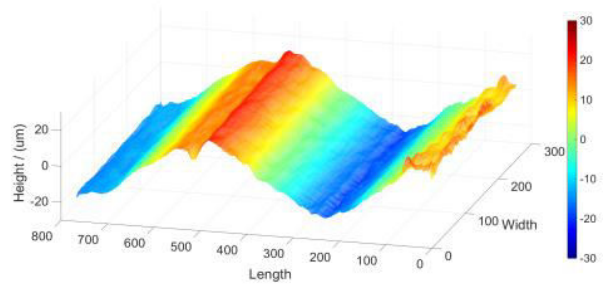

(a)

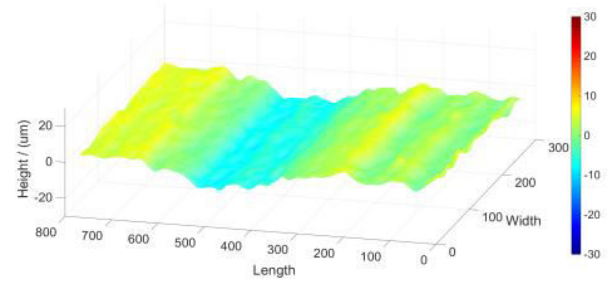

(b)

Fig. 17: Surface roughness of single crystal silicon with $\mathrm{Vx}=0.75 \mathrm{~mm} / \mathrm{min}$ and (a) $\mathrm{Vs}=$ $1.5 \mathrm{~m} / \mathrm{s}$, (b) varies wire velocity.

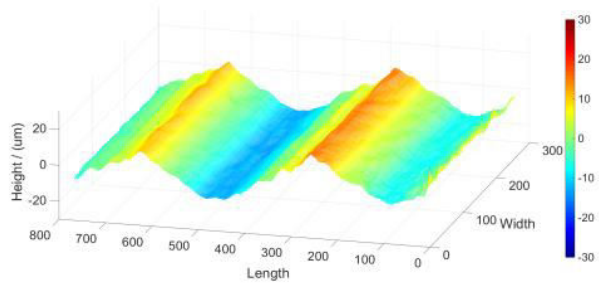

(a)

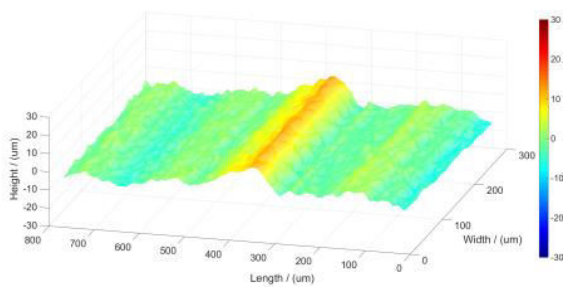

(b)

Fig. 18: Surface roughness of single crystal silicon with $\mathrm{Vx}=0.75 \mathrm{~mm} / \mathrm{min}$ and (a) $\mathrm{Vs}=$ $2.0 \mathrm{~m} / \mathrm{s}$, (b) varies wire velocity.

Table 2: Comparing the cutting time and surface roughness with and without wire velocity control (feed rate is $0.75 \mathrm{~mm} / \mathrm{min}$ )

\begin{tabular}{cccccccccc}
\hline \multicolumn{3}{c}{ Constant wire velocity } & \multicolumn{3}{c}{ Varies wire velocity } & \multicolumn{2}{c}{ Comparison $(\%)$} \\
$\begin{array}{c}\text { Wire } \\
\text { velocity } \\
(\mathrm{m} / \mathrm{s})\end{array}$ & $\begin{array}{c}\text { Normal } \\
\text { force } \\
(\mathrm{N})\end{array}$ & $\begin{array}{c}\text { Time } \\
(\mathrm{s})\end{array}$ & $\begin{array}{c}\text { Surface } \\
\text { roughne } \\
\text { ss }(\mu \mathrm{m})\end{array}$ & $\begin{array}{c}\text { Reference } \\
\text { force }(\mathrm{N})\end{array}$ & $\begin{array}{c}\text { Time } \\
(\mathrm{s})\end{array}$ & $\begin{array}{c}\text { Surface } \\
\text { roughne } \\
\text { ss }(\mu \mathrm{m})\end{array}$ & $\begin{array}{c}\text { Time } \\
(\mathrm{s})\end{array}$ & $\begin{array}{c}\text { Surface } \\
\text { roughnes } \\
\mathrm{s}(\mu \mathrm{m})\end{array}$ \\
\hline 1 & 2.720 & 2538 & 12.42 & 2.3 & 2111 & 6.25 & 16.8 & 49.6 \\
1.5 & 2.195 & 2314 & 9.98 & 2.0 & 2079 & 3.53 & 10.2 & 64.6 \\
\hline
\end{tabular}




\begin{tabular}{lllllllll}
\hline 2 & 1.746 & 2161 & 6.11 & 1.7 & 2006 & 2.85 & 7.2 & 53.3 \\
\hline
\end{tabular}

From the Table 2, the cutting time between constant wire velocity and varies wire velocity changes very small, from $6.5 \%$ to $16.4 \%$, the reason is the constant feed rate lead to the same cutting time. The surface roughness between constant wire velocity and varies wire velocity changes magnificently, $50 \%$ increase on average approximately, the reason is the control wire velocity make the cutting process more stable and the cutting force fluctuation smaller than the constant wire velocity, which lead to the smaller surface roughness and better surface roughness, and comparing the surface roughness in Fig. 16-18, the surface roughness with control wire velocity is smaller.

\subsection{The tangential force control experiment}

Figure 19 shows the control results when reference normal forces is \pm 0.7 and $\pm 0.45 \mathrm{~N}$, respectively. From the Fig. 19 , the controller start to regulate the wire velocity at 300 , and 400 s when reference tangential forces is 0.45 and $0.7 \mathrm{~N}$, respectively. When each wire saw change direction, the force is up and down which makes the difference between measured force and reference force change constantly which shows the controller work well. 

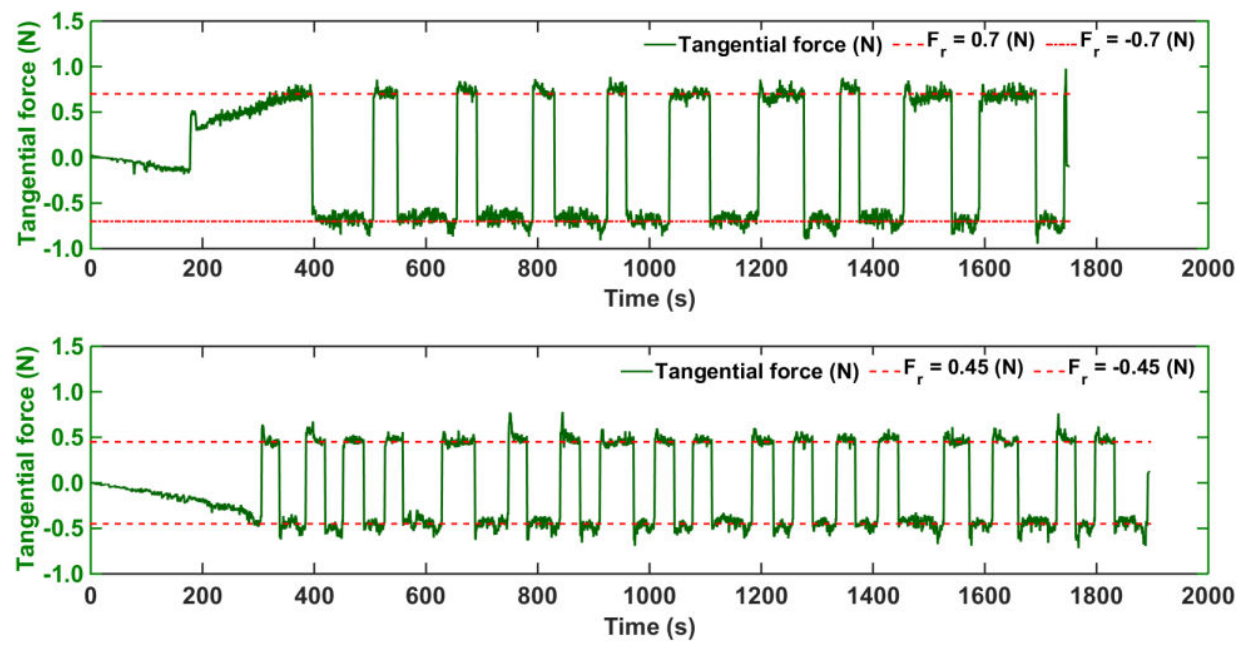

Fig. 19: the control results when reference tangential forces is \pm 0.45 and $\pm 0.7 \mathrm{~N}$.

Figure 20 shows the relationship between tangential force and nominal command wire saw velocity. During the cutting process, the wire saw velocity is varies with tangential force. At the beginning of cutting, the tangential force is small, according the control model, the small wire saw velocity could enlarge the cutting force. Therefore, the smaller wire saw velocity lead to the longer cutting period. As shows in Fig. 20 during 1000s to 1200 s.
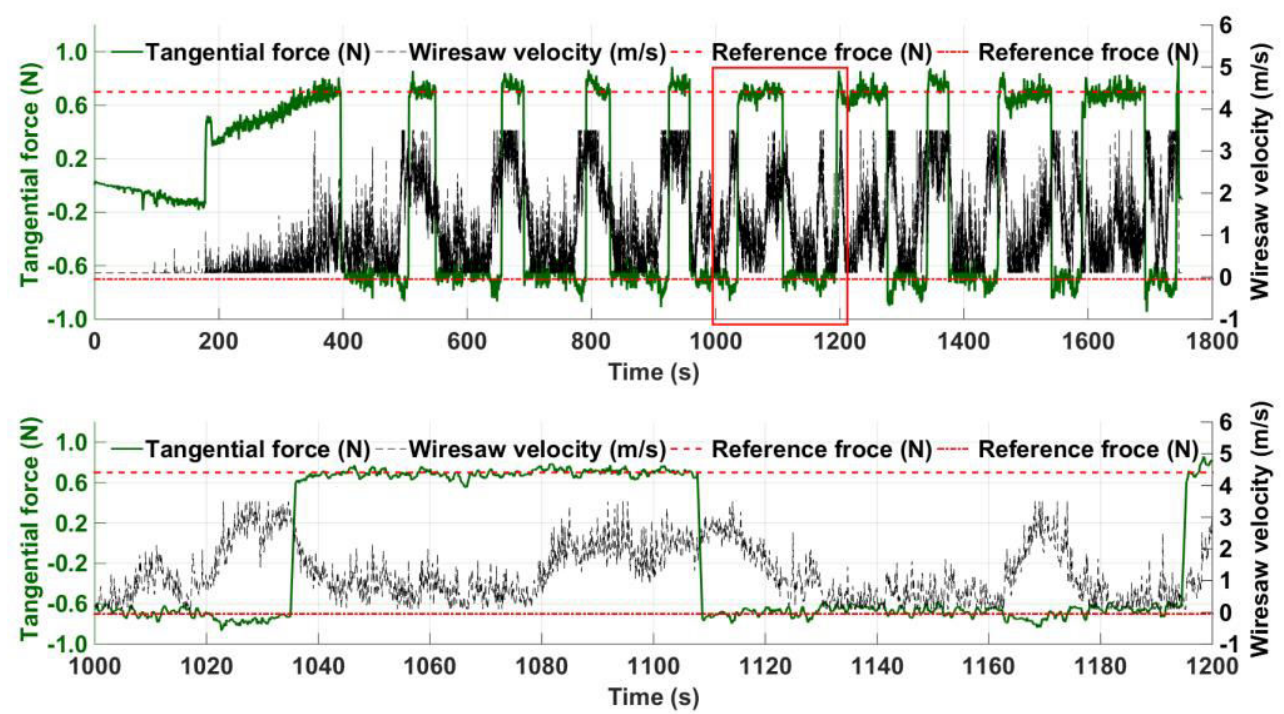

Fig. 20: The relation between tangential force and command wire velocity with reference force $\pm 0.7 \mathrm{~N}$. 
Figure 21 shows the tangential force comparison between control process and no control process. The control experiment time is $30 \%$ less than constant experiment.

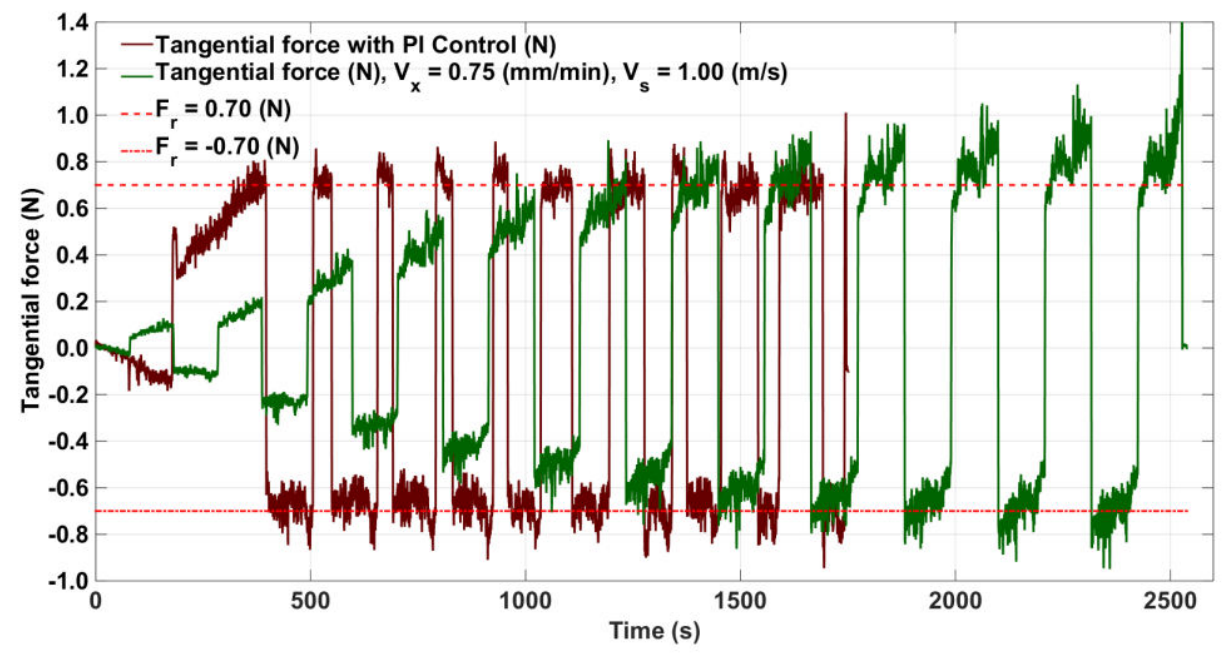

Fig. 21: The relation between tangential force and command wire velocity with reference force $\pm 0.7 \mathrm{~N}$.

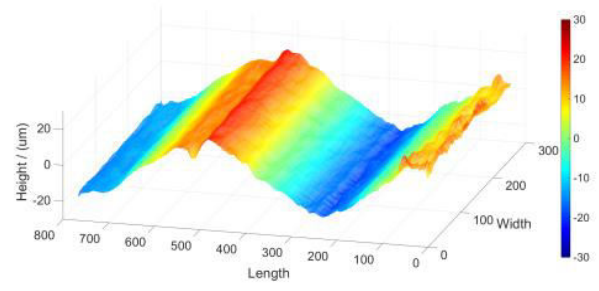

(a)

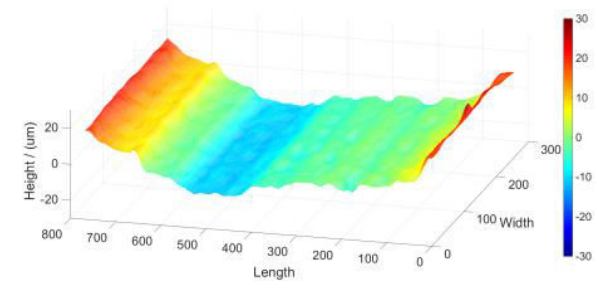

(b)

Fig. 22: Surface roughness of single crystal silicon with $V_{x}=0.75 \mathrm{~mm} / \mathrm{min}$ and (a) $V_{s}=1.5$ $\mathrm{m} / \mathrm{s}$, (b) varies wire velocity.

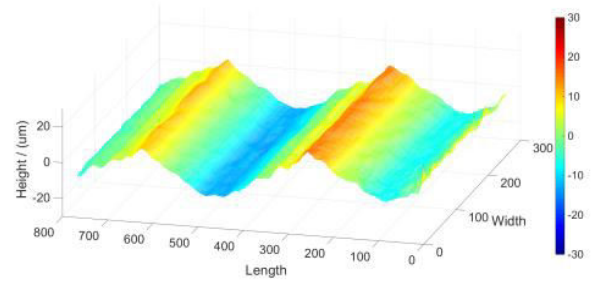

(a)

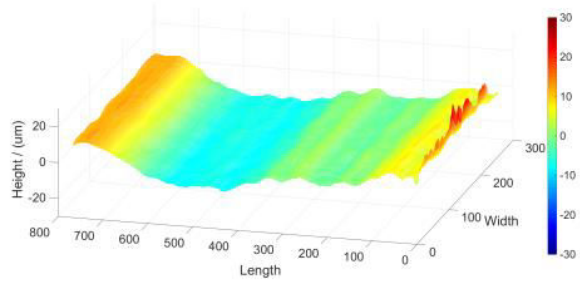

(b)

Fig. 23: Surface roughness of single crystal silicon with $V_{x}=0.75 \mathrm{~mm} / \mathrm{min}$ and (a) $V_{s}=2$ $\mathrm{m} / \mathrm{s}$, (b) varies wire velocity.

Table 3: Comparing the Cutting time and Surface roughness with and without wire 
velocity control (Part feed rate is $0.75 \mathrm{~mm} / \mathrm{min}$ )

\begin{tabular}{cccccccccc}
\hline \multicolumn{3}{c}{ Constant wire velocity } & \multicolumn{4}{c}{ Control wire velocity } & \multicolumn{2}{c}{ Comparison (\%) } \\
$\begin{array}{c}\text { Wire } \\
\text { velocity } \\
(\mathrm{m} / \mathrm{s})\end{array}$ & $\begin{array}{c}\text { Tangential } \\
\text { force }(\mathrm{N})\end{array}$ & $\begin{array}{c}\text { Time } \\
(\mathrm{s})\end{array}$ & $\begin{array}{c}\text { Surface } \\
\text { roughne } \\
\mathrm{ss}(\mu \mathrm{m})\end{array}$ & $\begin{array}{c}\text { Referenc } \\
\text { e force } \\
(\mathrm{N})\end{array}$ & $\begin{array}{c}\text { Time } \\
(\mathrm{s})\end{array}$ & $\begin{array}{c}\text { Surface } \\
\text { roughne } \\
\text { ss }(\mu \mathrm{m})\end{array}$ & $\begin{array}{c}\text { Time } \\
(\mathrm{s})\end{array}$ & $\begin{array}{c}\text { Surface } \\
\text { roughnes } \\
\mathrm{s}(\mu \mathrm{m})\end{array}$ \\
\hline 1 & 0.692 & 2538 & 9.98 & 0.7 & 1762 & 6.25 & 30.6 & 37.4 \\
2 & 0.395 & 2161 & 6.11 & 0.45 & 1892 & 4.72 & 26.1 & 22.7 \\
\hline
\end{tabular}

From Table 3, the cutting time between constant wire and varies wire velocity changes, from $26.1 \%$ to $30.3 \%$. At the same part feed rate, the cutting time decreases with the increase of the wire velocity. Comparing wire velocity control and constant wire velocity, at the early stage of cutting, the control wire saw velocity is reduced to increase the cutting force, so that the cutting force quickly reaches the reference force, thus improving the cutting efficiency, making the cutting time reduced. e.g., In the case of $F_{r}=0.7 \mathrm{~N}$, the cutting time is reduced by about $30 \%$. Meanwhile, the adjustment of wire saw velocity causes the cutting cycle of the wire saw to change, the length of the single cycle of the saw is constant. With the wire saw velocity increases, the cycle cutting time decreases, with the wire saw velocity decreases, the cycle cutting time increases.

\subsection{Analysis control results of the normal and tangential force}

Comparing the velocity control effect of the wire saw on the normal force and the tangential force, the corresponding $\mathrm{PI}$ controller is designed to conduct the control experiment, and the results show:

(1) For normal force control, compared with the constant parameter 
cutting process, the wire velocity control can reduce the fluctuation of the cutting force that is fluctuate near the reference, and the cutting time is slightly reduced. The surface roughness of the wafer is about $50 \%$ higher than that of the constant wire saw velocity.

(2) For tangential force control, the tangential force could be constant during the cutting process, and the wire velocity changes affect the cutting cycle, resulting in non-periodic grooves on the wafer surface, and then gets an improvement of the profile of the wafer surface, and the cutting time is a less than the constant wire velocity.

\section{Summary and Conclusions}

This paper investigates the effect of wire velocity on cutting force, which includes normal force and tangential force. In order to make the cutting process more stable, using $\mathrm{PI}$ controller to regulate the force via wire velocity control. The experimental studies for crystal silicon wafer wire saw machining are conducted. The following conclusions can be drawn from this work:

(1) The results show the PI controller can characterizes the normal force generated when wire saw machining crystal silicon and demonstrate that the wire saw machining process with normal force control significantly decrease wafer surface roughness as compared to the cutting process with a constant wire velocity reciprocation, which is about $50 \%$.

(2) For the wire saw velocity control of tangential force, the PI controller could demonstrate that the wire saw machining process with force control 
significantly improve the productivity as compared to the cutting process with a constant wire velocity reciprocation, which is from $16.1 \%$ to $34.7 \%$. Meanwhile, the surface roughness becomes better.

\section{Acknowledgements}

The authors wish to acknowledge the financial support for this work from the National Natural Science Foundation of China (51575442) and the Key program of Shaanxi Province (2021GY-275).

Funding: The research is financially supported by the National Natural Science Foundation of China (Grant No. 51575442), and the Shaanxi Province Key Research and Development Plan Project of China (Grant No. 2021GY-275).

Conflicts of interesting: The authors declare that they have no known competing financial interests or personal relationships that could have appeared to influence the work reported in this paper.

Availability of data and material: All data generated or analyzed during this study are included in this published article.

Code availability: Not applicable.

Ethics approval: Not applicable.

Consent to participate: Not applicable.

Consent for publication: All authors have read and agreed to the published 
version of the manuscript.

Authors' contributions: Jiabin Wang: Conceptualization, Code program, Writing original draft. Lie Liang: Modeling of cutting force, Investigation. Zheng Hao: Formal analysis, Experiments. Feilong Liu: Methodology, Writing -review \& editing. Shujuan Li: Formal analysis, Funding acquisition, Supervision, Validation, Writing -review \& editing. All authors read and approved the manuscript.

\section{References}

[1] CLARK W I, SHIH A J, HARDIN C W, et al. Fixed abrasive diamond wire machining-part I: process monitoring and wire tension force [J]. International Journal of Machine Tools and Manufacture, 2003, 43(5): 523-32.

[2] YUKARI ISHIKAWA Y-Z Y, YOSHIHIRO SUGAWARA, KOJI SATO, YOSHIHIRO OKAMOTO, NORITAKA HAYASHI, BENJAMIN DIERRE, KENTARO WATANABE, AND TAKASHI SEKIGUCHI. Comparison of slicing-induced damage in hexagonal SiC by wire sawing with loose abrasive, wire sawing with fixed abrasive, and electric discharge machining [J]. Japanese Journal of Applied Physics, 2014, 53: 071301-11.

[3] WATANABE N, KONDO, Y., IDE, D. MATSUKI, T., TAKATO, H., AND SAKATA, I. Characterization of polycrystalline silicon wafers for solar cells sliced with novel fixed-abrasive wire [J]. Progress in Photovoltaics: Research and Application, 2010, 18(7): 485-90.

[4] YIN Y, GAO Y, WANG L, et al. Analysis of crack-free surface generation of photovoltaic polysilicon wafer cut by diamond wire saw [J]. Solar Energy, 2021, 216: 245-58.

[5] CHUNG C, TSAY G D, TSAI M-H. Distribution of diamond grains in fixed abrasive wire sawing process $[\mathrm{J}]$. The International Journal of Advanced Manufacturing Technology, 2014, 73(9): 1485-94.

[6] CLARK W I, SHIH A J, LEMASTER R L, et al. Fixed abrasive diamond wire machining — part II: experiment design and results [Z]. International Journal of Machine Tools and Manufacture. 2003: 533-42.10.1016/s0890-6955(02)00216-X

[7] LI W-C, TSAI D-M. Automatic saw-mark detection in multicrystalline solar wafer images [J]. Solar Energy Materials and Solar Cells, 2011, 95(8): 2206-20.

[8] CAO L. Research on the Hydraulic Control System of diamond wire saw.pdf [J]. Proceedings of the IEEE International Conference on Automation and Logistics, Shenyang, China August 2009, 2009: 652-7. 
[9] ZHU L, KAO I. Galerkin-based modal analysis on the vibration of wire-slurry system in wafer slicing using a wiresaw [J]. Journal of Sound and Vibration, 2005, 283(3-5): 589-620.

[10] LIEDKE T, KUNA M. A macroscopic mechanical model of the wire sawing process [J]. International Journal of Machine Tools and Manufacture, 2011, 51(9): 711-20.

[11] SHUJUAN LI S D, AOFEI TANG AND ROBERT G. LANDER. Force Modeling and Control of SiC Monocrystal Wafer Processing [J]. Transaction of ASME, Journal of Manufacturing Science and Engineering, 2015.

[12] LI S, WANG J, AN B, et al. Wire saw cutting force modeling and control using wire saw velocity [J]. Proceedings of the International Symposium on Flexible Automation, 2018.

[13] YOSHINO M, SIVANANDAM A, KINOUCHI Y, et al. Critical Depth of Hard Brittle Materials on Nano Plastic Forming [J]. Journal of Advanced Mechanical Design, Systems, and Manufacturing, 2008, 2(1): 59-70.

[14] LI S, TANG A, LIU Y, et al. Analytical Force Modeling of Fixed Abrasive Diamond Wire Saw Machining With Application to SiC Monocrystal Wafer Processing [J]. Journal of Manufacturing Science and Engineering, 2016, 139(4): 041003.

[15] LI Z, GE P, BI W, et al. Influence of silicon anisotropy on surface shape deviation of wafer by diamond wire saw [J]. Materials Science in Semiconductor Processing, 2021, 133.

[16] LI S, WANG J, TANG A, et al. Force modeling of silicon monocrystal wire saw machining [Z]. 2016 International Symposium on Flexible Automation (ISFA). 2016: 127-32.10.1109/isfa.2016.7790148 